\title{
PENATAAN KAWASAN CAGAR BUDAYA BETAWI CONDET CILIWUNG, JAKARTA TIMUR, SEBAGAI DESTINASI WISATA ALAM DAN BUDAYA
}

\author{
Verani Nurizki ${ }^{11}$, Suryono Herlambang ${ }^{2)}$, Parino Rahardjo ${ }^{3)}$
}

1)Program Studi S1 PWK, Fakultas Teknik, Universitas Tarumanagara, veraninur@gmail.com

2)Program Studi S1 PWK, Fakultas Teknik, Universitas Tarumanagara, s.herlambang@gmail.com

3)Program Studi S1 PWK, Fakultas Teknik, Universitas Tarumanagara, parinor19@gmail.com

Masuk: 10-08-2020, revisi: 07-09-2020, diterima untuk diterbitkan: 25-09-2020

\begin{abstract}
Abstrak
Kawasan Condet memiliki keterkaitan erat dengan peradaban Budaya Betawi di Jakarta. Pada tahun 1976, Kawasan Condet ditetapkan sebagai Cagar Budaya namun status tersebut kemudian dicabut pada tahun 1988 karena dianggap membatasi perkembangan Kawasan Condet. Kawasan Condet kembali menjadi perhatian setelah diterbitkannya Keputusan Gubernur Provinsi DKI Jakarta No. 881 Tahun 2019 yang menetapkan pengembangan wisata berupa pengembangan seni budaya Betawi, agrowisata serta ekowisata di Kawasan Condet. Permasalahan yang ditemukan berupa keunikan eksisting yang tersebar di Kawasan Ciliwung Condet seperti rumah Betawi, Komunitas Ciliwung Condet, Kebun Salak dan festival-festival di kawasan tersebut dapat menjadi daya tarik kawasan namun belum dimanfaatkan dengan maksimal dan fakta yang pernah terjadi ketika Kawasan Condet menjadi cagar budaya dianggap membatasi perkembangan Kawasan Condet serta pemakaian badan jalan sebagai lokasi Festival Condet. Penelitian ini bertujuan untuk menentukan potensi dan masalah yang ada di Kawasan Ciliwung Condet, menentukan halhal yang mendukung Kawasan Ciliwung Condet menjadi destinasi wisata serta usulan penataan Kawasan Ciliwung Condet sebagai destinasi wisata. Penataan Kawasan dapat mengusung konsep eco-cultural, yaitu konsep yang memadukan aspek ekologis dan budaya dari sebuah lanskap untuk membuat sebuah situs. Penelitian dilakukan menggunakan pendekatan kualitatif, salah satunya melalui wawancara mendalam (indepth interview) yang dijabarkan menggunakan metode deskriptif. Hasil dari penelitian ini berupa rencana induk penataan Kawasan Wisata Ciliwung Condet.
\end{abstract}

\section{Kata kunci: Kawasan Ciliwung Condet; Kawasan Cagar Budaya; Penataan Destinasi Wisata; Tepian Sungai}

\begin{abstract}
Condet area has close links with Betawi Cultural civilization in Jakarta. In 1976, Condet Area was designated as a Cultural Heritage but the status was later revoked in 1988 because it was considered to limit the development of the Area. Condet area returned to attention after the issuance of the Governor of DKI Jakarta Province No. 881 of 2019 which stipulated the development of tourism in the form of the development of Betawi cultural arts, agro-tourism and ecotourism in Condet Area. The problems found are existing uniqueness scattered in the Ciliwung Condet area such as Betawi homes, Ciliwung Condet Community, Salak Gardens and festivals in the area that can be the main attraction but have not been fully utilized and facts that have occurred when the Condet Area became a cultural heritage considered limiting the development of the Area and the use of road bodies as the location for the Condet Festival. This study aims to determine the potential and problems that exist in the Ciliwung Condet Area, determine the things that support the Area to become a tourist destination and to propose the arrangement of the Area as a tourist destination. The arrangement can carry an eco-cultural concept, which is a concept that combines ecological and cultural aspects of a landscape to create a site. The research was conducted using a qualitative approach, one of which was through in-depth interviews described using descriptive methods. The results of this study are in the form of a master plan for the arrangement of the Ciliwung Condet Tourism Area.
\end{abstract}




\section{PENDAHULUAN}

\section{Latar Belakang}

Kota Jakarta Timur memiliki potensi pengembangan pariwisata, salah satunya adalah Kawasan Condet yang kaya akan budaya. Kawasan Condet dikenal memiliki keterkaitan erat dengan budaya Betawi yang ada di Jakarta (Taranggono, 1992) . Kawasan Condet sempat dinobatkan sebagai cagar budaya pada tahun 1976 karena memiliki keunikan budaya Betawi serta buah khasnya yaitu Salak Condet. Namun, status tersebut dicabut karena dianggap membatasi perkembangan Kawasan Condet. Pada tahun 2019, Kawasan Condet kembali diperhatikan dengan keluarnya Keputusan Gubernur DKI Jakarta Nomor 881 Tahun 2019 yang menetapkan pengembangan tiga jenis wisata berupa seni budaya Betawi,agrowisata dan ekowisata.

\section{Rumusan Masalah}

Hingga kini Kawasan Condet belum dikembangkan sesuai dengan arahan Rencana Tata Ruang Wilayah (RTRW) DKI Jakarta Tahun 2012-2030 dan Keputusan Gubernur Nomor 881 Tahun 2019 Tentang Tim Percepatan Penataan dan Pengembangan Kawasan Condet Sebagai Destinasi Wisata. Selain itu, keunikan-keunikan eksisting yang tersebar di Kawasan Ciliwung Condet seperti rumah asli Betawi yang masih tersisa, Komunitas Ciliwung Condet, kebun salak Condet dan festival-festival yang terdapat di Kawasan Ciliwung Condet yang dapat menjadi daya tarik kawasan belum dimanfaatkan dengan maksimal, selain itu fakta yang pernah terjadi pada Kawasan Condet saat warga sekitar tidak setuju ketika dijadikan sebagai kawasan cagar budaya karena dianggap membatasi perkembangan Kawasan Condet dan penggunaan badan Jalan Condet Raya sebagai lokasi Festival Condet menjadi permasalahan yang menarik di Kawasan Ciliwung Condet.

\section{Tujuan}

Penelitian ini bertujuan untuk menentukan potensi dan masalah di Kawasan Ciliwung Condet,hal-hal yang dapat mendukung Kawasan Condet sebagai destinasi wisata serta usulan penataan Kawasan Condet sebagai destinasi wisata. Batasan objek studi ini adalah Kawasan Condet dengan area perencanaan di Kelurahan Balekambang seluas 37,9 ha.

\section{KAJIAN LITERATUR}

\section{Sungai}

Sungai didefinisikan sebagai bagian dari permukaan bumi yang letaknya lebih rendah dari tanah di sekitarnya dan menjadi tempat mengalirnya air tawar menuju ke laut, danau, rawa atau ke sungai lain (Syarifuddin, 2000). Sungai memiliki beberapa bagian seperti sempadan sungai, bantaran sungai dan palung yang dapat dilihat pada gambar berikut:

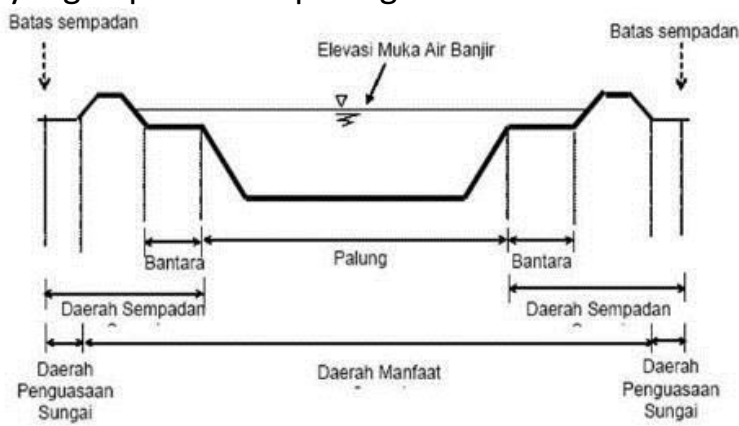

Gambar 1. Bagian Sungai

Sumber : Dinas PUP\&ESDM DIY, 2013

Berdasarkan pasal 1 Peraturan Pemerintah Republik Indonesia Nomor 38 Tahun 2011 yang dikeluarkan oleh Kementerian Sekretariat Negara RI, sempadan sungai diartikan sebagai garis maya yang terletak di kiri dan kanan palung sungai yang ditetapkan sebagai batas perlindungan 
sungai (Republik Indonesia, 2011). Pada pasal 9 garis sempadan sungai tidak bertanggul di dalam kawasan perkotaan ditentukan sebagai berikut:

a. Paling sedikit berjarak 10 meter dari tepi kiri dan kanan palung sungai sepanjang alur sungai, kedalaman sungai kurang dari atau sama dengan 3 meter.

b. Paling sedikit berjarak 15 meter dari tepi kiri dan kanan palung sungai sepanjang alur sungai, kedalaman lebih dari 3 meter sampai dengan 20 meter, dan

c. Paling sedikit berjarak 30 meter dari tepi kiri dan kanan palung sungai sepanjang alur sungai, kedalaman sungai lebih dari 20 meter.

Palung sungai menurut Pasal 4 huruf a Peraturan Republik Indonesia Nomor 38 Tahun 2011 berfungsi sebagai ruang wadah air mengalir dan sebagai tempai berlangsungnya ekosistem sungai.

\section{Kepariwisataan}

Pariwisata didefinisikan sebagai kegiatan perjalanan yang dilakukan oleh seseorang atau sekelompok orang dengan mengunjungi tempat tertentu untuk tujuan rekreasi, pengembangan pribadi, atau mempelajari keunikan daya tarik wisata yang dikunjungi dalam jangka waktu sementara (Republik Indonesia, 2009).

\section{Daya Tarik Wisata}

Terdapat 4 komponen yang harus dimiliki oleh sebuah objek wisata (Cooper, Fletcher, Gilbert, \& Wanhill, 1995), yaitu :

a. Attraction (Atraksi), seperti alam yang menarik, kebudayaan daerah yang menawan dan seni pertunjukkan.

b. Accessibility (Aksesibilitas), seperti transportasi yang menunjang kemudahan untuk bergerak dari daerah yang satu ke daera tujuan wisata

c. Amenity (Fasilitas), seperti segala macam sarana dan prasarana yang diperlukan oleh wisatawan selama berda di daerah tujuan wisata. Sarana dan prasarana dapat berupa penginapan, rumah makan, transportasi dan agen perjalanan.

d. Ancillary (Pelayanan Tambahan), seperti hal-hal yang mendukung pariwisata seperti Tourist Information, Agent Travel dan Stakeholderl yang berperan dalam kepariwisataan.

\section{Prasarana dan Sarana Kepariwisataan}

Prasarana pariwisata adalah fasilitas yang memungkinkan proses kegiatan pariwisata dapat berjalan dengan lancar sehingga dapat memudahkan setiap orang yang terlibat dalam kegiatan berwisata (Suwena I.K, 2017). Prasarana dikelompokkan menjadi dua jenis yaitu:

a. Prasarana umum berupa fasilitas umum yang haru ada di daerah tuuan wisata antara lain pembangkit tenaga listrik, penyediaan air bersih, jaringan jalan raya, stasiun kereta api, pelabuhan laut, bandara dan fasilitas komunikasi.

b. Prasarana kebutuhan masyarakat banyak berupa rumah sakit, apotek, kantor pos, bank, pompa bensin.

\section{Konsep Eco-Cultural}

Eco-Cultural merupakan bentuk baru dari kegiatan wisata dimana aspek ekologis dan budaya dari sebuah lanskap dikombinasikan untuk membuat situs untuk turis. Hal ini dapat dijelaskan sebagai perjalanan ke tujuan dimana sokongan dari alam dan budaya merupakan daya tarik utama dan dianggap sebagai sebuah strategi potensial untuk keberlanjutan ekonomi. Oleh karena itu alat untuk pemberdayaan ekonomi dan pengembangan masyarakat adat yang membuat tradisi hidup dan mendukung perlindungan warisan alam dan budaya sehingga meningkatkan apresiasi pengunjung (Lipman, 1996). 


\section{Penataan}

Penataan ruang merupakan suatu sistem proses perencanaan tata ruang, pemanfaatan ruang, dan pengendalian pemanfaatan ruang (Republik Indonesia, 2007).

\section{Konsep Zonasi Perencanaan Kawasan Pariwisata}

Konsep zonasi pada perencanaan kawasan pariwisata terdapat dua jenis (Wardhono, 2015), yaitu:

1) Tripartite Concept

a. Core Zone atau Main Zonei, merupakan zona inti atau atraksi sebuah kawasan pariwisata yang harus tetap terjaga dan memberi khas atau tema kawasan pariwisata tersebut. Building ratio antara $10 \%-20 \%$ dari luas keseluruhan.

b. Buffer Zone, merupakan zona penyangga berupa natural yang berbentuk lanskap yang berfungsi sebagai penyangga atau penyeimbang untuk aktivitas maupun fasilitas yang ada di kawasan tersebut. Building ratio antara $60 \%-80 \%$ dari luas keseluruhan.

c. Service Zone atau Public Zone, merupakan zona pelayanan yang biasanya digunakan untuk pengembangan fasilitas dan pelayanan untuk dikomersilkan.

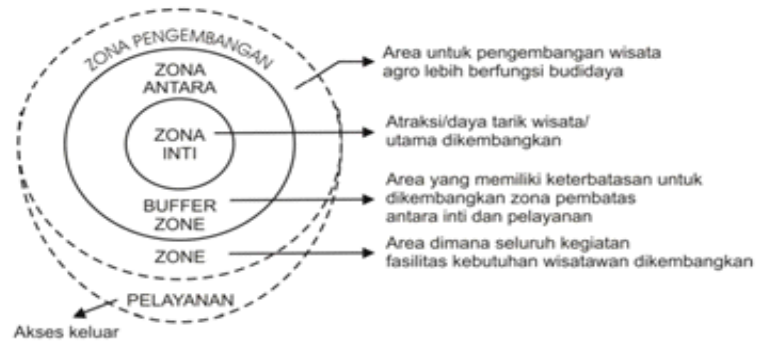

Gambar 2. Konsep Tripartite

Sumber : Wallace, 1995 dalam Gunarto,2009

2) Concept of Honey Pot

Konsep ini mengkonsentrasikan fasilitas, prasarana, dan aktivitas pengunjung pada suatu area. Konsep ini diterapkan pada daerah yang memiliki tingkat kepadatan yang tinggi baik penduduk, aktivitas, maupun bangunan dan lokasinya berdekatan dengan pusat aksesibilitas.

\section{METODE}

Penulis mengggunakan pendekatan kualitatif dengan penjabaran melalui metode deskriptif. Metode deskriptif juga menginterpretasikan data-data dan informasi yang didapat dari hasil in depth interview dengan cara mewawancara pihak terkait atau stakeholder di Kawasan Ciliwung Condet yaitu Komunitas Ciliwung Condet dan Yayasan Cagar Budaya Betawi Condet. Lokasi penelitian terletak di Kawasan Condet dengan area perencanaan di Kelurahan Balekambang dengan batas bagian barat adalah Sungai Ciliwung, timur adalah Kelurahan Batu Ampar, utara Kelurahan Cililitan dan selatan adalah Kelurahan Gedong, Kecamatan Pasar Rebo.

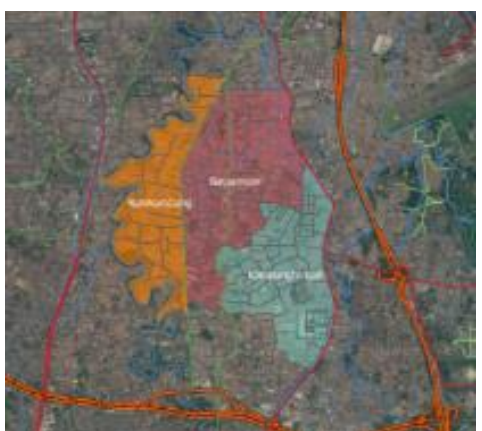

(a)

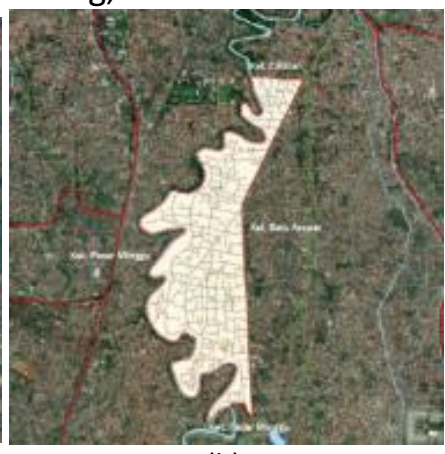

(b)

Gambar 3. Lokasi Penelitian (a) Kawasan Condet (b) Kelurahan Balekambang Sumber : Olahan Penulis, 2020 
Teknik pengumpulan data yang dilakukan adalah sebagai berikut:

a. Teknik Pengumpulan Data Primer

1) Survey Lapangan, merupakan salah satu metode pengamatan langsung pada objek penelitian yang dilakukan oleh peneliti untuk mendapatkan data secara langsung dengan tujuan untuk mengetahui kondisi eksisting objek yang akan diteliti yaitu Kawasan Ciliwung Condet.

2) Wawancara Mendalam (In Depth Interview), yaitu proses wawancara dengan pihak yang terkait dengan pengembangan Kawasan Ciliwung Condet. Pihak tersebut adalah Komunitas Ciliwung Condet dan Yayasan Cagar Budaya Betawi Condet.

3) Dokumentasi mencakup foto kondisi eksisting, foto fisik, masalah dan foto lingkungan di sekitar area penataan.

b. Teknik Pengumpulan Data Sekunder

Teknik pengumpulan data sekunder merupakan metode pencarian data dari sumber terkait dengan objek studi berupa data dari instansi pemerintah maupun pemerintdah, serta studi literatur, buku, jurnal, skripsi dan informasi dari internet.

\section{DISKUSI DAN HASIL}

Kawasan Condet berdasarkan SK Gubernur DKI Jakarta tanggal 18 Desember 1975 D.I.7903a/30/1975 terdiri atas tiga wilayah yaitu Kelurahan Baru Ampar, Kelurahan Balekambang dan Kelurahan Kampung Tengah. Situs prasejarah berdasarkan Peta Persebaran situs prasejarah di Kawasan Condet oleh Hasan Djafar (1988) banyak ditemukan di sepanjang Sungai Ciliwung, Kelurahan Balekambang. Sungai Ciliwung Condet sendiri memiliki panjang 12 $\mathrm{km}$ yang terbentar dari Jembatan Kalibata hingga Jembatan TB Simatupang yang melewati Kelurahan Cawang, Kelurahan Cililitan, Kelurahan Balekambang dan Kelurahan Gedong (Kecamatan Pasar Rebo).

\section{Analisis Kebijakan}

Berdasarkan RTRW DKI Jakarta, Kawasan Condet diakui sebagai jalur wisata bagian timur dan merupakan salah satu lokasi cagar budaya yang akan dilestarikan, keputusan tersebut didukung dengan terbitnya Keputusan Gubernur DKI Jakarta No. 881 Tahun 2019 tentang Tim Percepatan Penataan dan Pengembangan Kawasan Condet sebagai destinasi wisata. Namun, kebijakankebijakan tersebut belum terlaksana akibat kurang bersinerginya stakeholder terkait yaitu pemerintah, pihak komunitas dan warga setempat.

\section{Analisis Lokasi dan Proximity}

Kelurahan Balekambang memiliki luas wilayah sebesar 167 ha terbagi menjadi 5 Rukun Warga (RW) juga memiliki lokasi yang sangat strategis karena dengan dengan pusat-pusat kegiatan di sekitar seperti Pusat Grosir Cililitan (PGC), Pasar Induk Kramat jati, Bandara Halim Perdana Kusuma, Universitas Kristen Indonesia, Taman Mini Indonesia Indah dan Ragunan serta akses pintu masuk tol. 


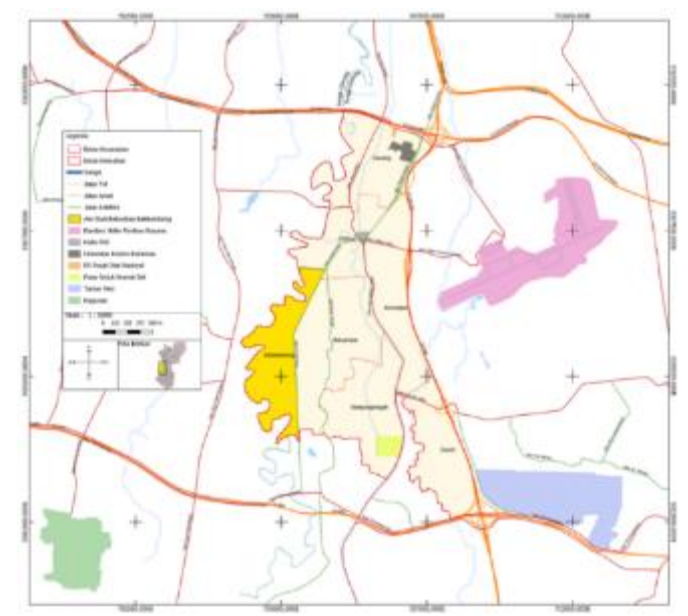

Gambar 4. Analisis Lokasi dan Proximity

Sumber : Olahan Penulis, 2020

Namun, lokasi kelurahan Balekambang hanya dilewati oleh angkutan umum mikro yaitu KWK T07 rute PGC - Condet dan memiliki lokasi rawan banjir yang terletak pada RW 01 dan 05 yang terletak di sepanjang Sungai Ciliwung dengan ketinggian berkisar 0-250 cm. Kelurahan Balekambang juga hanya memiliki exposure terhadap Jalan Condet Raya yang menyebabkan akses masuk kawasan hanya terdapat dari Jalan Condet Raya dan nilai lahan cenderung tinggi pada area sekitar Jalan Condet Raya saja.

\section{Analisis Tapak}

Kelurahan Balekambang dibagi menjadi 3 area perencanaan, pada area perencanaan tersebut hanya memiliki exposure dan akses masuk dari arah Jalan Condet Raya saja yang menyebabkan nilai lahan tinggi pada area sekitar Jalan Condet Raya. Pada tapak area perencaan 01 dan 02 terdapat area RW 01 dan 05 yang merupakan lokasi banjir di Kelurahan Balekambang. Selain itu, terdapat Garis Sempadan Sungai (GSS) selebar $10 \mathrm{~m}$ (berdasarkan Pasal 1 Peraturan Pemerintah Nomor 38 Tahun 2011 pasal 9) dari tepi palung sungai yang dapat dimanfaatkan menjadi area hijau/resapan air. Diketahui pula bahwa nilai lahan cenderung menurun ke arah barat ( Sungai Ciliwung) dan banyak ditemui lahan dengan status tidak terdaftar.

\section{Analisis Aktivitas Wisata}

Kelurahan Balekambang memiliki aktivitas yang berpotensi untuk dikembangkan menjadi aktivitas wisata. Aktivitas di Kelurahan Balekambang didominasi oleh jenis darmawisata (bersifat rekreasi) seperti festival tahunan yaitu Festival Condet, Festival Ciliwung dan Kebun Salak Condet. Aktivitas lain yang terdapat pada area tersebut adalah haul/maulid tahunan serta lokasi dari rumah asli Betawi yang masih terjaga keasriannya hingga saat ini. Pada Kelurahan Balekambang (Kawasan Ciliwung Condet) dapat dikembangkan kegiatan yang dapat mendorong pariwisata berupa pelayaran dan eksplorasi sungai, memancing, pusat kebudayaan, kuliner khas Betawi, festival kebudayaan, fieldtrip kebun salak, belanja buah khas Condet dan Pusat Pelestarian Flora dan Fauna. 


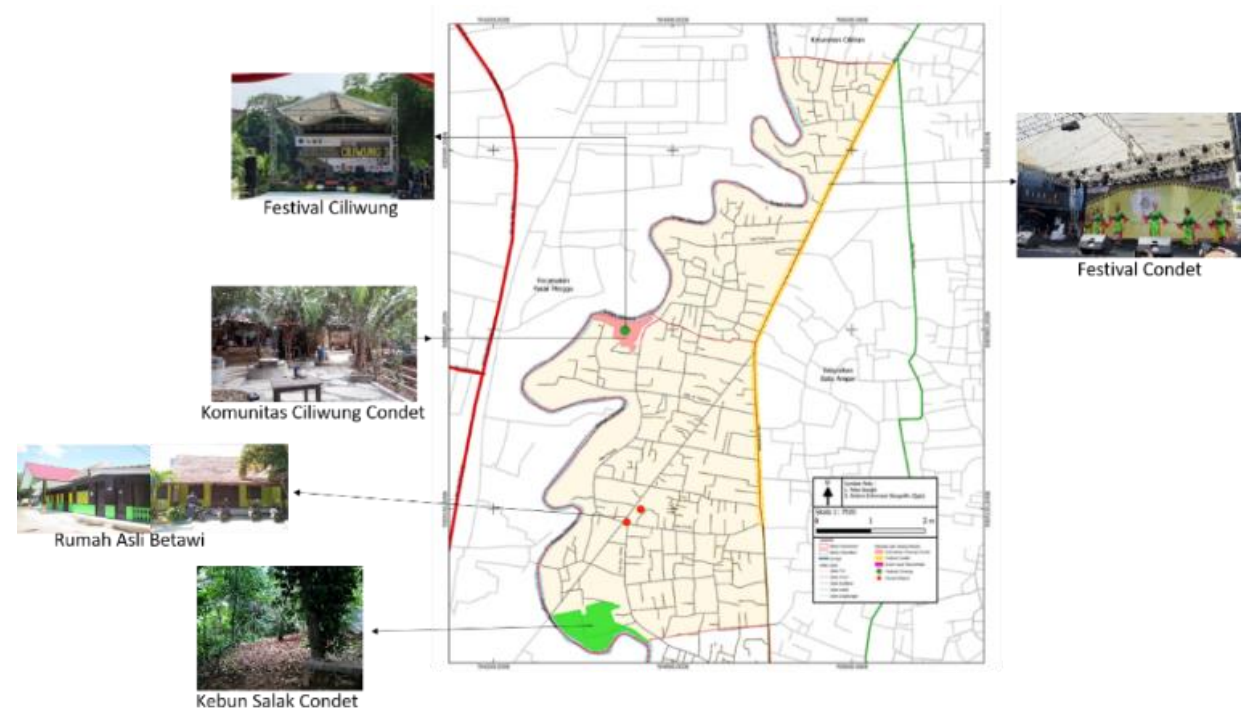

Gambar 5. Peta Analisis Aktivitas Wisata

Sumber : Olahan Penulis, 2020

\section{Analisis Benchmarking}

Fasilitas yang dapat diterapkan berdasarkan yang dibandingkan dari Kampung Budaya Setu Babakan dan Kampung Batik Laweyan adalah gerbang masuk, area parkir, dermaga, sepeda air, pusat pendidikan dan pelatihan seni budaya Betawi, gedung serbaguna, area rekreasi, gazebo, musholah dan toilet.

\section{Analisis Kebutuhan Ruang}

Berdasarkan analisis kebutuhan ruang, penulis mendapati bahwa jumlah pengunjung harian hanya didasarkan pada data event tahunan yaitu Festival Condet. Festival Condet berlangsung selama 2 hari dengan pengunjung mencapai 1,1 juta orang yang berlangsung dari pukul 08.00 WIB - 21.30 WIB terletak di Jalan Condet Raya dengan panjang $\pm 1,9 \mathrm{~km}$ dengan area seluas $13,469 \mathrm{~m}^{2}$ atau sekitar 1,3 ha. Namun, bila didasarkan pada data tersebut pengunjung hanya mendapatkan ruang gerak sebesar $0,1 \mathrm{~m}^{2}$, dimana standar dimensi gerak luar ruangan seharusnya sebesar $1,5 \mathrm{~m}^{2}$ per pengunjung. Maka penulis melakukan asumsi sebagai berikut:

a. Festival Condet akan direlokasi pada jalan sepanjang $3.836 \mathrm{~m}^{2}$ (3,8 kilometer) dengan lebar $9 \mathrm{~m}$ pada lokasi yang direncanakan sehingga terdapat ruang untuk festival sebesar $34.524 \mathrm{~m}^{2}$ $(3,4 \mathrm{ha})$

b. Terdapat kebun salak Condet seluas $33.378 \mathrm{~m}^{2}$ (3,3 ha)

c. Terdapat ruang sebesar $67.902 \mathrm{~m}^{2}$ yang merupakan pertambahan dari area lokasi rencana festival dan area kebun salak eksisting.

d. Kebutuhan ruang tersebut dibagi dengan standar ruang gerak luar ruangan sebesar $1,5 \mathrm{~m}^{2}$ per pengunjung, sehingga jumlah pengunjung harian adalah sebesar 45.268 pengunjung.

e. Ketika event Festival Condet berlangsung, pengujung diasumsikan dibagi menjadi 3 sif yaitu pada pukul $08.00-12.00$ WIB, $13.00-17$ WIB, dan 18.00 - selesai dengan jumlah pengujung sebesar 271.608 pengunjung dalam 2 hari.

Penulis mengusulkan area penataan dengan luas total $379.114 \mathrm{~m}^{2}$ atau 37,9 ha yang akan direncanakan menjadi 3 area berdasarkan kriteria berikut ini: 
Tabel 1. Pembagian Area Pada Kawasan Wisata Ciliwung Condet

\begin{tabular}{|c|c|c|c|}
\hline Area & Fungsi & Kriteria & Aktivitas \\
\hline Pendukung & Komersial & $\begin{array}{l}\text { - Tidak berada di sempadan sungai (10 meter } \\
\text { dari palung sungai) } \\
\text { - Terdapat area parkir }\end{array}$ & $\begin{array}{l}\text { Kegiatan perdagangan dan jasa (jual } \\
\text { beli) }\end{array}$ \\
\hline \multirow[b]{2}{*}{ Rekreasi } & Komersial & $\begin{array}{l}\text { - Tidak berada di sempadan sungai (10 meter } \\
\text { dari palung sungai) } \\
\text { - Terdapat area parkir }\end{array}$ & $\begin{array}{l}\text { Kegiatan perdagangan dan jasa (jual } \\
\text { beli) }\end{array}$ \\
\hline & Rekreasi & $\begin{array}{l}\text { - Dekat dengan spot aktivitas sungai (air) } \\
\text {-Terdapat kolam pemancingan } \\
\text {-Terdapat Pusat Edukasi } \\
\text {-Terdapat area parkir }\end{array}$ & $\begin{array}{l}\text { - Kegiatan wisata sungai seperti } \\
\text { sepeda air } \\
\text { - Kegiatan memancing } \\
\text { - Kegiatan menikmati pemandangan } \\
\text { alam } \\
\text { - Bersantai }\end{array}$ \\
\hline \multirow{2}{*}{$\begin{array}{l}\text { Lindung dan } \\
\text { Budaya }\end{array}$} & Budaya & $\begin{array}{l}\text { - Lokasi dekat dengan wisata rumah Betawi } \\
\text { - Terdapat panggung pertunjukan dan } \\
\text { amphiteather } \\
\text { - Terdapat atribut budaya Betawi } \\
\text { - Terdapat area pakir }\end{array}$ & $\begin{array}{l}\text { - Edukasi budaya Betawi } \\
\text { - Menikmati kuliner khas Betawi }\end{array}$ \\
\hline & Lindung & $\begin{array}{l}\text { - Merupakan area pelestarian Salak Condet } \\
\text { - Kawasan yang berfungsi sebagai area } \\
\text { resapan air dan tempat parkir air } \\
\text { - Terdapat area parkir }\end{array}$ & $\begin{array}{l}\text { - Menikmati pemandangan alam } \\
\text { - Penjelajahan kebun salak / fieldtrip } \\
\text { - Jual beli tanaman hias khas Betawi }\end{array}$ \\
\hline
\end{tabular}

Sumber : Olahan Penulis, 2020

Pada area tersebut akan dilengkapi oleh sarana dan prasarana seperti tempat parkir dan jalur pedestrian serta fasilitas seperti pusat informasi, toilet, kafe/tempat makan, pusat souvenir, ATM Centre,gazebo, musholah, pos keamanan, Pusat Pelestarian Flora dan Fauna Ciliwung Condet, Pusat Pendidikan dan Pelatihan Kebudayaan Betawi Condet, Pusat Jajanan Khas Betawi, Amphitheathre, Panggung Pentas, Klinik, Loket, Gudang Sepeda Air dan Kolam Pemancingan yang direncanakan sebagai berikut:

Tabel 2. Perhitungan Rencana Kebutuhan Ruang Fasilitas

\begin{tabular}{|c|c|c|c|c|c|c|}
\hline Peruntukan & Area/Bangunan & $\begin{array}{l}\text { Presentase } \\
\text { Pengguna } \\
(\%) \\
\end{array}$ & $\begin{array}{c}\text { Jumlah } \\
\text { Pengguna } \\
\text { (Pengunjung) }\end{array}$ & $\begin{array}{l}\text { Jumlah } \\
\text { Unit }\end{array}$ & $\begin{array}{l}\text { Total } \\
\text { Luas } \\
\left(\mathrm{m}^{2}\right)\end{array}$ & Presentase \\
\hline \multicolumn{5}{|c|}{ Total Lahan } & 379,114 & $100 \%$ \\
\hline \multicolumn{5}{|c|}{ Lahan Efektif } & 34,784 & $9 \%$ \\
\hline \multirow{14}{*}{ Fasilitas } & Pusat Informasi & - & - & 2 & 224 & $0.64 \%$ \\
\hline & Toilet & $0.25 \%$ & 113 & 14 & 345 & $0.99 \%$ \\
\hline & ATM Center & - & - & 2 & 64 & $0.18 \%$ \\
\hline & Gazebo & $5 \%$ & 2263 & 226 & 2,260 & $6.50 \%$ \\
\hline & Musholah & $0.25 \%$ & 113 & 4 & 840 & $2.41 \%$ \\
\hline & Pos Keamanan & - & - & 3 & 38 & $0.11 \%$ \\
\hline & $\begin{array}{l}\text { Pusat Pendidikan dan } \\
\text { Pelatihan Kebudayaan } \\
\text { Betawi Condet }\end{array}$ & - & - & 1 & 3,409 & $9.80 \%$ \\
\hline & $\begin{array}{l}\text { Pusat Jajanan Khas } \\
\text { Betawi }\end{array}$ & $5 \%$ & 2263 & 1 & 6,336 & $18.22 \%$ \\
\hline & Amphiteatre & $0.40 \%$ & 200 & 1 & 100 & $0.29 \%$ \\
\hline & $\begin{array}{l}\text { Panggung Rigging } \\
\text { Permanen }\end{array}$ & - & - & 1 & 48 & $0.14 \%$ \\
\hline & Klinik & - & - & 1 & 150 & $0.43 \%$ \\
\hline & Loket & - & - & 2 & 12 & $0.03 \%$ \\
\hline & Gudang Sepeda Air & - & - & 1 & 80 & $0.23 \%$ \\
\hline & Kolam Pemancingan & & & 1 & 5,000 & $14.37 \%$ \\
\hline
\end{tabular}




\begin{tabular}{|c|c|c|c|c|c|c|}
\hline Peruntukan & Area/Bangunan & $\begin{array}{c}\text { Presentase } \\
\text { Pengguna } \\
(\%)\end{array}$ & $\begin{array}{c}\text { Jumlah } \\
\text { Pengguna } \\
\text { (Pengunjung) }\end{array}$ & $\begin{array}{l}\text { Jumlah } \\
\text { Unit }\end{array}$ & $\begin{array}{l}\text { Total } \\
\text { Luas } \\
\left(\mathrm{m}^{2}\right)\end{array}$ & Presentase \\
\hline \multicolumn{5}{|c|}{ Lahan Non Efektif } & 272,867 & $72 \%$ \\
\hline \multirow{4}{*}{$\begin{array}{c}\text { Sarana } \\
\text { Infrastruktur/ } \\
\text { Taman/ } \\
\text { Landsekap, } \\
\text { Open Space. } \\
\text { RTH }\end{array}$} & Jalan dan Pedestrian & - & - & - & 57,119 & $21 \%$ \\
\hline & Parkir & - & - & - & 47,135 & $17 \%$ \\
\hline & $\begin{array}{c}\text { Kebun Salak Condet dan } \\
\text { area Konservasi }\end{array}$ & - & - & - & 158,255 & $58 \%$ \\
\hline & Ruang terbuka hijau & - & - & - & 10,358 & $4 \%$ \\
\hline \multicolumn{6}{|c|}{ Total Penggunaan Lahan } & $81 \%$ \\
\hline
\end{tabular}

Sumber : Olahan Penulis, 2020

\section{Konsep dan Perencanaan}

Kawasan Ciliwung Condet akan ditata berdasarkan konsep eco-cultural yang memadukan aspek budaya (Budaya Betawi Condet) dan bentang alam (Sungai Ciliwung dan Kebun Salak Condet) dengan rencana penataan sebagai berikut :

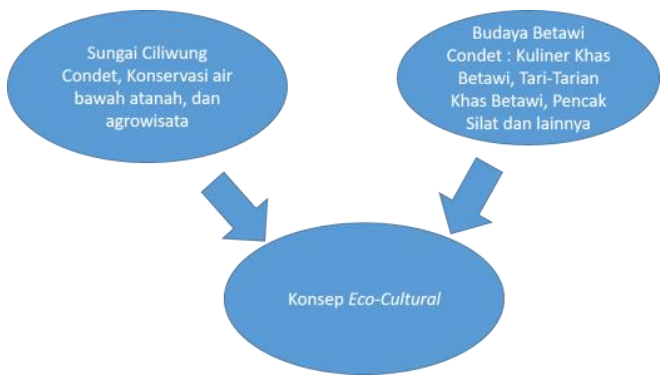

Gambar 6. Aspek Eco Cultural

Sumber : Olahan Penulis, 2020

Konsep penataan disusun berdasarkan hasil analisis dan tiga permasalahan utama yang terdapat di Kawasan Ciliwung Condet yaitu keunikan-keunikan eksisting yang belum dimanfaatkan dengan maksimal, terdapat lokasi banjir serta lokasi Festival Condet yang dianggap mengganggu arus lalu lintas. Ketiga permasalahan tersebut dikelompokkan dalam empat topik konsep yang penulis kombinasikan dengan 3 prinsip eco-cultural yaitu konservasi warisan alam dan budaya lokal, partisipasi masyarakat lokal dan manfaat sosial ekonomi dan keikutsertaan para pelaku/stakeholder. Konsep pertama merupakan konsep dasar yang akan menjadi acuan dalam penyusunan rencana-rencana lainnya.

Tabel 3. Rencana Penataan Berdasarkan Konsep

\begin{tabular}{|c|c|c|}
\hline Konsep & Penjelasan & Implementasi \\
\hline $\begin{array}{l}\text { Konsep Utama: } \\
\text { Pelestarian Alam }\end{array}$ & $\begin{array}{l}\text { Pada Kawasan Kelurahan } \\
\text { Balekambang yang tertuang di RDTR } \\
\text { DKI Jakarta } 2030 \text { terdapat banyak } \\
\text { area hijau dengan kode } \mathrm{H} 2, \mathrm{H} 3, \mathrm{H} 4 \text { dan } \\
\mathrm{H} 5 \text { didominasi oleh kode } \mathrm{H} 4 \text { yang } \\
\text { merupakan jalur hijau dengan } \\
\text { intensitas KDB, KLB,KB, KDH dan KB } \\
\text { sebesar 0. Selain itu, pada keadaan } \\
\text { eksisiting terdapat kebun salak baik } \\
\text { yang dikelola oleh pemetintah daerah } \\
\text { maupun kebun warga yang } \\
\text { seharusnya dilindungi untuk menjaga } \\
\text { populasi Salak Condet. Konsep ini } \\
\text { memberikan arahan untuk } \\
\text { meningkatkan nilai keindahan dari } \\
\text { bentang Sungai Ciliwung Condet serta } \\
\text { melindungan eksistensi Salak Condet } \\
\text { dan area-area hijau agar tetap asri }\end{array}$ & $\begin{array}{l}\text { a. Membuat fungsi lindung sesuai dengan area hijau pada } \\
\text { RDTR } 2030 \text {. Fungsi lindung memiliki intensitas } \\
\text { KDB,KLB,KB,KDH dan KB sebesar } 0 \text {. } \\
\text { b. Adanya sempadan sungai sebagai floodplain dengan } \\
\text { lebar } 10 \text { meter sesuai dengan Pasal } 9 \text { Peraturan } \\
\text { Pemerintah RI No. } 38 \text { Tahun } 2011 \text {. } \\
\text { c. Jalanan yang terletak setelah sempadan tidak } \\
\text { menggunakan perkerasan beton. } \\
\text { d. Menggunakan jenis drainase tertutup dengan penyaring } \\
\text { pada saluran paling akhir yang terhubung langsung } \\
\text { dengan Sungai Ciliwung. } \\
\text { e. Untuk menunjang keamanan, dibuat pembatas antara } \\
\text { sempadan sungai dengan pedestrian berupa semak } \\
\text { seperti tanaman bougenville. } \\
\text { f. Penyediaan jalur pergerakan non motor (pejalan kaki) } \\
\text { yang saling terkoneksi dalam kawasan. } \\
\text { g. Menggunakan teknologi dan material yang ramah } \\
\text { lingkungan terutama untuk fasilitas pendukung. }\end{array}$ \\
\hline
\end{tabular}




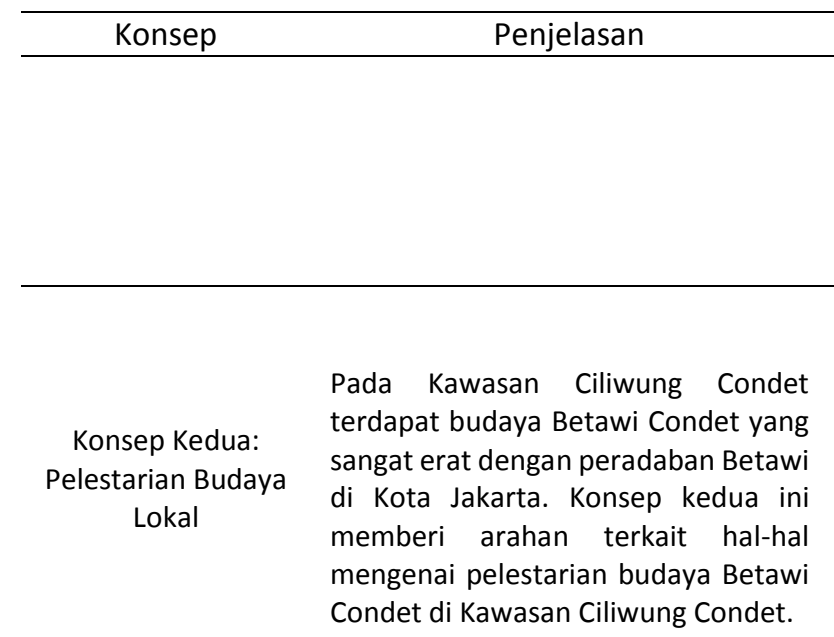

h. Mendukung kegiatan pelestarian alam, salah satunya Festival Ciliwung yang bertujuan untuk memperkenalkan kembali Sungai Ciliwung Condet.

i. Membuat Pusat Pelestarian Flora dan Fauna sebagai sarana edukasi masyarakat dan wadah berkumpul komunitas pecinta lingkungan.

a. Membuat fungsi budaya yang di dalamnya terdapat kegiatan edukasi Budaya Betawi Condet.

b. Pada fungsi budaya, dilengkapi oleh atribut khas Betawi.

c. Membuat Pusat Pendidikan dan Pelatihan Kebudayaan Betawi Condet yang mewadahi segala bentuk kegiatan kebudayaan Betawi.

d. Membuat pusat kuliner dan souvernir khas Betawi.

e. Adanya kegiatan budidaya tanaman hias khas Betawi yang dapat diperjual belikan kepada pengunjung.

f. Mengadakan kegiatan festival kebudayaan yang bersifat tahunan seperti Festival Condet dan Festival Jadoel.

Konsep ini memberi penekanan detail pada pelaku kegiatan wisata yang diutamakan merupakan warga lokal

Konsep Ketiga: Keikutsertaan Para Pelaku/Stakeholder dengan tujuan untuk meningkatkan nilai ekonomi, selain itu komunitas juga turut andil dalam aktivitas wisata sesuai dengan bidangnya baik pada bidang budaya maupun lingkungan dan terakhir adalah pemerintah sebagai regulator.

Kawasan Wisata Ciliwung Condet diarahkan untuk pengembangan aktivitas wisata yang didasarkan oleh aktivitas wisata eksisting yang telah ada dalam bentuk baru terkait Kebun Salak Condet, Rumah Betawi Condet, Komunitas Ciliwung Condet, dan Festival-festival yang ada di Kawasan

Konsep Keempat: Pengembangan Pariwisata.
Ciliwung Condet. Selain itu, keragaman wisata juga dapat ditingkatkan dengan menambahkan aktivitas lain yang dapat dilakukan dalam kawasan ini. Konsep ini juga terkait dengan arahan pengadaan fasilitas yang mendukung aktivitas wisata tersebut. a. Pada aspek lingkungan dapat bekerjasama dengan Komunitas Ciliwung Condet dan komunitas sejenis dalam melakukan pengelolaan.

b. Pada aspek budaya dapat bekerjasama dengan Yayasan Komunitas Ciliwung Condet dan pihak sejenis dalam melakukan pengelolaan.

c. Pada pusat kuliner khas Betawi dan pusat souvenir mengutamakan produk buatan masyarakat lokal untuk meningkatkan perekonomian sekitar.

a. Membuat fungsi rekreasi yang merupakan area pengembangan aktivitas wisata.

b. Mengembangkan aktivitas wisata berdasarkan aktivitas eksisting seperti kegiatan susur sungai dan kunjungan ke rumah Betawi Aasli.

c. Mengembangkan atraksi sepeda air dan kolam pancing sebagai aktivitas wisata baru untuk menarik pengunjung.

d. Membuat fasilitas pendukung seperti kafe/tempat makan, musholah, ATM Centre, pusat informasi,klinik dan pos keamanan.

e. Membagi kawasan menjadi 3 area berdasarkan teori Tripartite Concept menjadi area pendukung, area rekreasi serta area lindung dan budaya guna memperjelas peletakan fasilitas pendukung sesuai dengan fungsi yang ada.

Sumber : Olahan Penulis, 2020

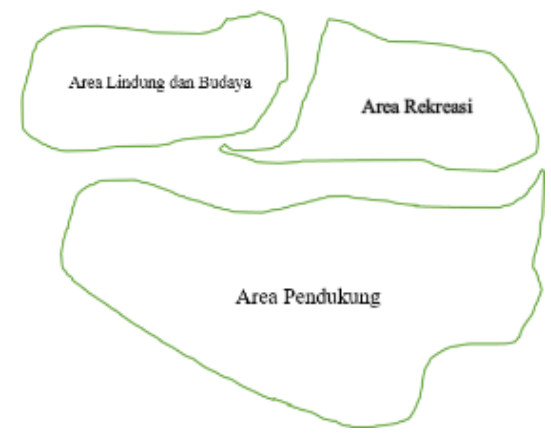

Gambar 7. Ilustrasi Pembagian Area Berdasarkan Teori Tripartite

Sumber : Olahan Penulis, 2020

Pembagian area pada Kawasan Ciliwung Condet didasarkan pada teori Tripartite Concept. Menurut Pada Kawasan Wisata Ciliwung Condet, area pendukung merupakan implementasi dari 
zona pelayanan, dimana aktivitas komersial umum dapat berlangsung namun tidak mengganggu fungsi lindung yang ada. Lalu area rekreasi yang merupakan implementasi dari zona penyangga, dimana fungsi rekreasi dikembangkan bersamaan dengan komersial umum dengan tema tertentu namun tetap terdapat fungsi lindung yang tidak diganggu. Dan terakhir adalah area lindung dan budaya yang merupakan implementasi dari zona inti, pada area ini terdapat atraksi utama di Kawasan Ciliwung Condet yaitu fungsi budaya (Betawi Condet) dan lingkungan (lanskap Kebun Salak Condet eksisting). Pada area lindung dan budaya, 3 prinsip pengembangan ecocultural dapat ditemukan seluruhnya.

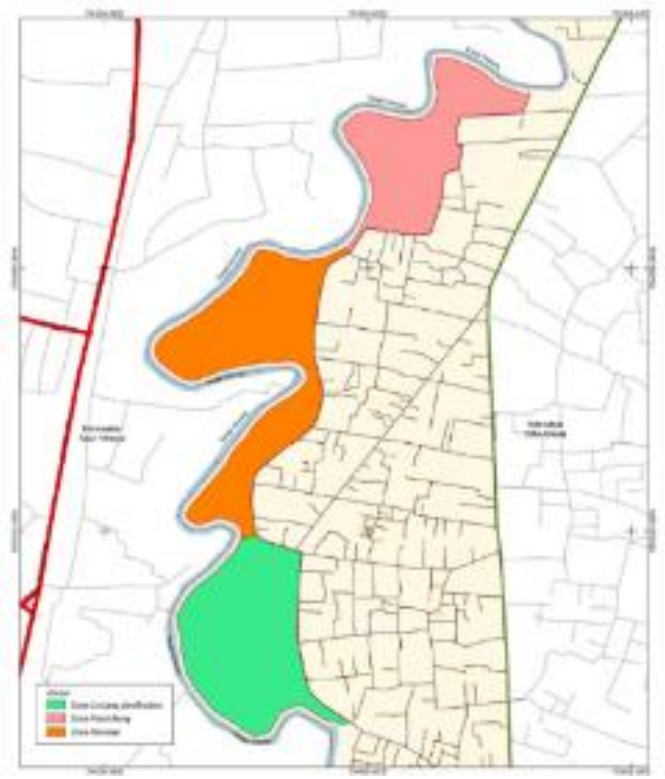

Gambar 8. Peta Rencana Pembagian Area Pada Kawasan Wisata Ciliwung Condet Sumber : Olahan Penulis, 2020

Zona pendukung merupakan area yang mendukung fungsi komerisal pada Kawasan Wisata Ciliwung Condet dengan luas \pm 10 ha. Pada Keadaan eksisting, zona ini merupakan area permukiman dan tidak terdapat objek khusus yang dilindungi ataupun aktivitas wisata. Pada zona ini direncanakan akses masuk 1 (utama) dan fasilitas berupa 6 unit toilet, 1 unit musholah, 2 unit tempat makan (umum), 1 unit tempat souvenir, 1 unit pusat informasi, 1 unit ATM Centre, 1 unit pos keamanan dan 30 unit gazebo. Zona Pendukung direncanakan sebagai berikut:

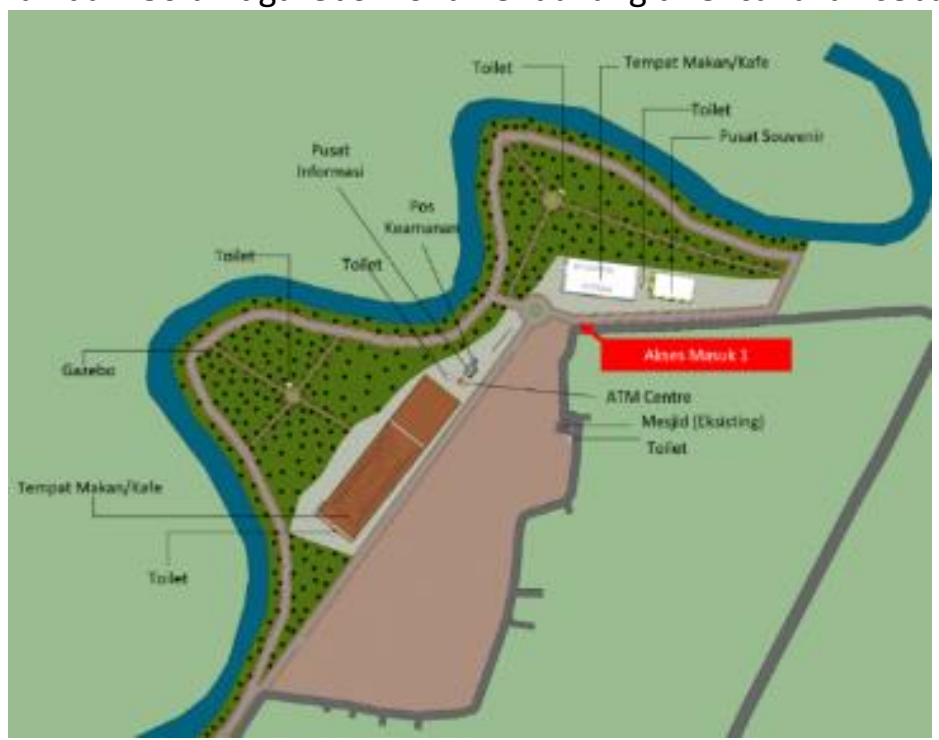

Gambar 9. Rencana Penataan Zona Pendukung Sumber : Olahan Penulis, 2020 
Zona rekreasi merupakan area yang mendukung fungsi rekreasi dan komersial pada Kawasan Wisata Ciliwung Condet dengan luas \pm 12.42 ha. Pada kondisi eksisting zona ini merupakan area permukiman dan terdapat aktivitas Komunitas Ciliwung Condet berupa sekolah alam dan kegiatan pelestarian Sungai Ciliwung. Salah satu kegiatan yang diadakan oleh Komunitas Ciliwung Condet berupa susur sungai yaitu kegiatan menyusuri Sungai Ciliwung, maka zona ini dapat dikembangkan sebagai zona rekreasi yang salah satu kegiatannya adalah susur sungai. Fasilitas yang direncanakan pada zona rekreasi adalah 4 unit toilet, 1 unit musholah, 1 unit tempat souvenir, 1 unit ATM Centre, 1 unit kafe/tempat makan tema outdoor, 1 unit klinik, 1 unit kolam pancing, 77 unit gazebo, 1 unit kolam ikan, 1 unit loket sepeda air, dan 1 unit dermaga sepeda air. Zona Rekreasi rencanakan sebagai berikut:

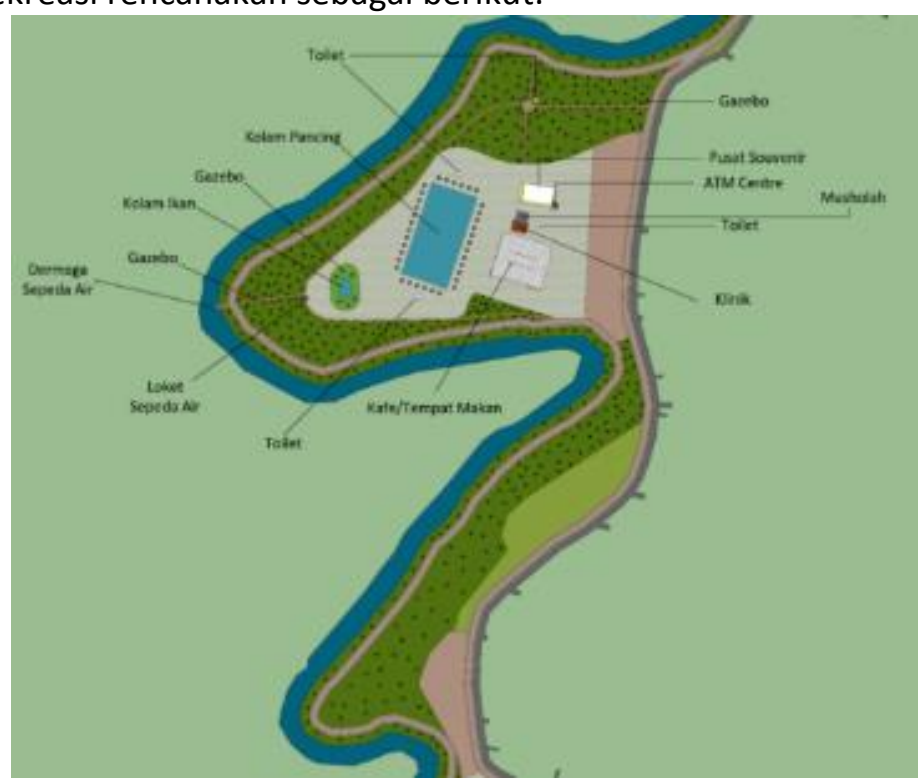

Gambar 10. Rencana Penataan Zona Rekreasi

Sumber: Olahan Penulis, 2020

Zona lindung dan budaya merupakan area yang mendukung fungsi lindung dan budaya pada Kawasan Wisata Ciliwung Condet dengan luas \pm 15.46 ha. Pada kondisi eksisting zona ini merupakan area permukiman namun terdapat aktivitas wisata berupa kebun buah Salak Condet serta dekan dengan lokasi dua unit rumah adat Betawi Condet asli yang masih tersisa. Pada zona ini direncanakan 3 akses masuk yang salah satunya dari arah barat (Kecamatan Pasar Minggu) yang merupakan akses eksisting (Jalan Jembatan). Fasilitas yang direncanakan pada zona rekreasi adalah 4 unit toilet, 2 unit musholah, 1 unit pusat kuliner khas Betawi, 1 unit Pusat Pendidikan dan Pelatihan Kebudayaan Betawi Condet, 1 panggung pentas, 1 unit amphitheatre, 1 unit loket sepeda air, 1 unit dermaga air, 1 unit gudang sepeda air, 1 kolam ikan, 1 unit pos kemanan, 1 unit Pusat Pelestarian Flora dan Fauna Ciliwung Condet dan 72 unit gazebo. 


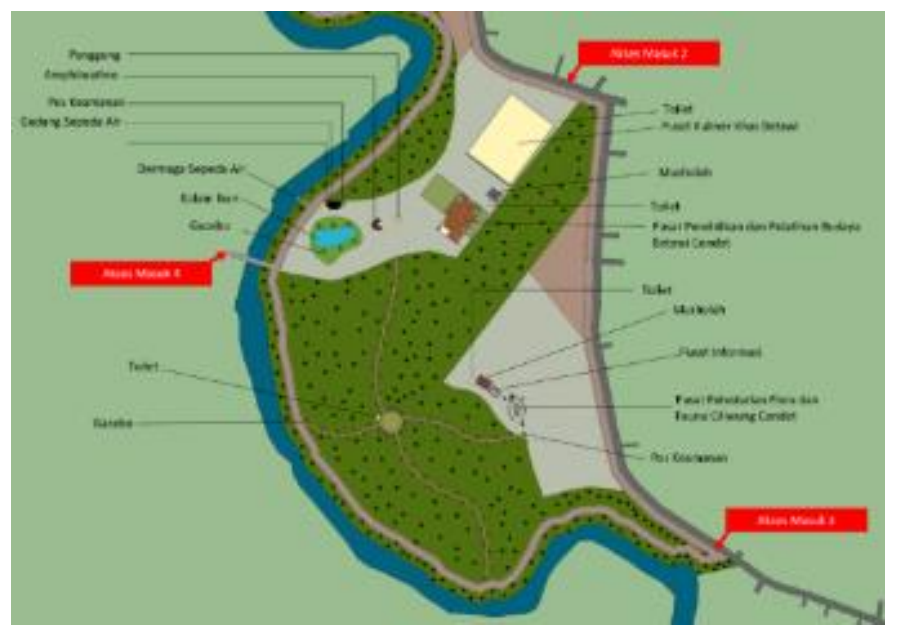

Gambar 11. Rencana Penataan Zona Lindung dan Budaya Sumber: Olahan Penulis, 2020

Pada area Edukasi lingkungan masih terdapat banyak area terbuka yang nantinya dimanfaatkan sebagai lokasi budidaya tanaman hias khas Betawi dan dapat menjadi lokasi dari suatu event. Berikut ini merupakan visualisasi dari fasilitas yang direncanakan pada Kawasan Wisata Ciliwung Condet :

Jalan pada Kawasan Wisata Ciliwung Condet direncanakan memiliki ROW selebar 9 meter yang digambarkan sebagai berikut:

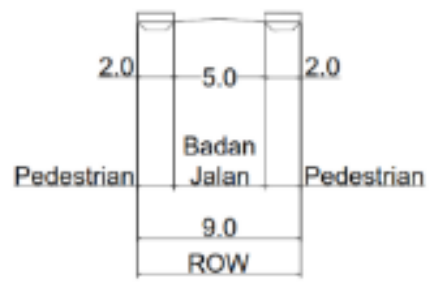

(a) Potongan Jalan Utama

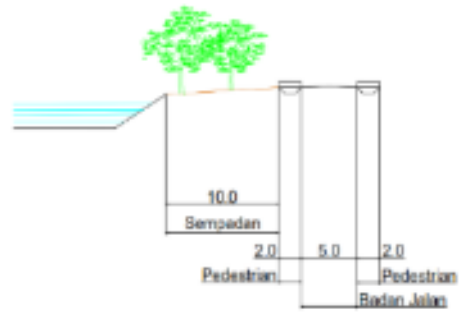

(b) Potongan GSS dan Jalan Sisi Sungai

Gambar 12. Rencana Jalan di Kawasan Wisata Ciliwung Condet

Sumber : Olahan Penulis, 2020

Festival Condet pada rencana Kawasan Wisata Ciliwung Condet akan digelar di sepanjang jalan pada sisi barat kawasan wisata yang menyusuri Sungai Ciliwung dengan jarak $3.836 \mathrm{~m}^{2}$ (3,8 $\mathrm{km}$ ) dengan lebar $9 \mathrm{~m}$.

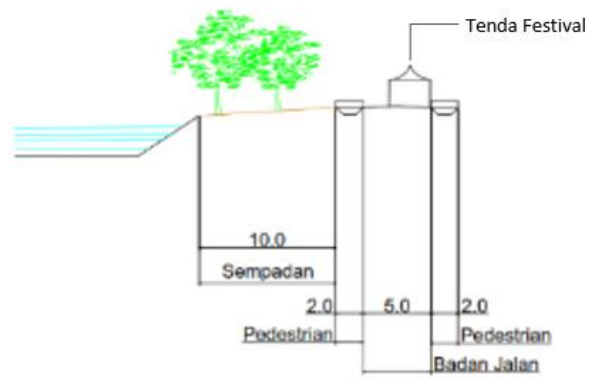

Gambar 13. Potongan Jalan Sisi Sungai Sebagai Lokasi Pemindahan Festival Condet Sumber : Olahan Penulis, 2020 


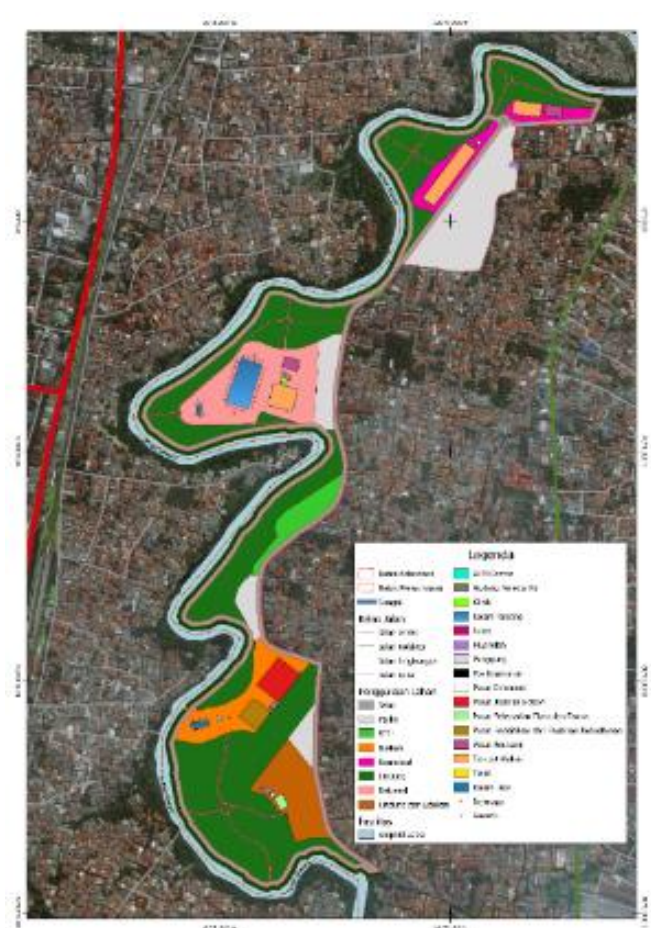

Gambar 14. Rencana Induk (Masterplan) Kawasan Wisata Ciliwung Condet Sumber: Olahan Penulis, 2020

\section{KESIMPULAN DAN SARAN}

Berdasarkan analisis kebijakan bahwa Kawasan Ciliwung Condet telah dipersiapkan menjadi salah satu destinasi wisata karena telah tertera dalam RTRW DKI Jakarta yang dipertegas oleh Keputusan Gubernur No. 881 Tahun 2019 Tentang Tim Percepatan Penataan dan Pengembangan Kawasan Condet Sebagai Destinasi Wisata. Berdasarkan analisis lokasi, Kawasan Ciliwung Condet terletak pada lokasi yang strategis karena dekat dengan pusat-pusat kegiatan disekitar serta lokasi pintu tol. Berdasarkan analisis tapak, Kawasan Ciliwung Condet terdapat garis sempadan sungai dengan jarak 10 meter dari tepi palung sungai yang berpotensi menjadi area hijau. Namun, pada Kawasan Ciliwung Condet juga terdapat permasalahan yang terjadi. Berdasarkan analisis kebijakan, belum terdapat penataan fisik yang berjalan karena kurang bersinerginya antar stakeholder. Selain itu, berdasarkan analisis lokasi didapati bahwa Kawasan Ciliwung Condet hanya dilewati oleh angkutan umum yang bersifat lingkungan dan tidak bersinggungan langsung dengan pintu tol. Pada Kawasan Ciliwung Condet juga terdapat lokasi banjir yang terletak pada RW 01 dan RW 02 Kelurahan Balekambang. Berdasarkan analisis tapak, permasalahan yang ditemukan berupa exposure yang hanya terdapat pada Jalan Condet Raya, sehingga nilai lahan hanya tinggi pada area sekitar Jalan Condet Raya.

Terdapat hal-hal yang dapat mendukung Kawasan Ciliwung Condet sebagai destinasi wisata. Berdasarakan analisis aktivitas wisata, terdapat kegiatan wisata eksisting yang didominasi oleh jenis darmawisata seperti kegiatan sekolah alam yang dijalankan oleh Komunitas Ciliwung Condet, wisata kebun buah Salak Condet yang dikelola oleh Dinas Kelautan, Pertanian dan Ketahanan Pangan Provinsi DKI Jakarta, Festival Condet dan Festival Jadoel yang ada diinisiasi oleh Yayasan Cagar Budaya Betawi Condet bekerja sama dengan Suku Dinas Pariwisata dan Kebudayaan Kota Jakarta Timur, Festival Ciliwung yang dinisiasi oleh Komunitas Ciliwung Condet bekerjasama dengan Suku Dinas Pariwisata dan Kebudayaan Kota Jakarta Timur dan acara haul/maulid tahunan yang diadakan oleh tokoh agama dan tokoh masyarakat sekitar. Pada Kawasan Ciliwung Condet juga dikembangkan kegiatan aktivitas wisata berupa pelayaran dan eksplorasi sungai, memancing, pusat kebudayaan, kuliner khas Betawi, festival kebudayaan, 
fieldtrip ke kebun salak, pusat pelestarian flora dan fauna serta aktivitas belanja buah khas Condet. Fasilitas yang dpaat diterapkan pada Kawasan Ciliwung Condet berupa gerbang masuk, area parkir, dermaga, sepeda air, pusat pendidikan dan pelatihan seni budaya Betawi, gedung serbaguna, area rekreasi, gaze, musholah dan toilet umum.

Berdasarkan potensi dan permasalah serta hal-hal yang mendukung Kawasan Ciliwung Condet sebagai destinasi wisata, usulan rencana Penataan Kawasan Ciliwung Condet dapat mengusung konsep eco-cultural dimana konsep tersebut memadukan potensi alam berupa bentang (Sungai Ciliwung dan Kebun Salak Condet) dan potensi budaya berupa Kebudayaan Betawi Condet. Area yang direncanakan sebesar $379.114 \mathrm{~m}^{2}$ atau 37,9 ha dengan pengunjung harian yang diasumsikan sebanyak 45.268 jiwa dan pengunjung saat event Festival Condet sebanyak 271.608 jiwa. Kawasan Wisata Ciliwung Condet direncanakan menjadi 3 zona yaitu zona pendukung dengan luas \pm 10 ha, zona rekreasi dengan luas \pm 12.42 ha dan zona lindung dan budaya dengan luas \pm 15.46 ha. Zona lindung dan budaya merupakan zona inti yang dilengkapi oleh nuansa khas Betawi. Luas area yang perlukan untuk fasilitas adalah $34.784 \mathrm{~m}^{2}$ atau 3,4 ha (9\% dari luas total area) dengan fasilitas yang direncanakan adalah 2 buah pusat informasi, 14 unit toilet, 3 unit kafe/tempat makan, 2 unit pusat souvenir khas Condet, 2 unit ATM centre, 226 unit gazebo, 4 unit musholah (terdapat 1 unit musholah eksisting), 3 unit pos keamanan, 1 unit pusat pelestarian flora dan fauna Ciliwung Condet, 1 unit pusat pendidikan dan pelatihan kebudayaan Betawi Condet, 1 unit pusat jajanan khas Betawi Condet, 1 unit amphiteatre, 1 unit panggung pentas, 1 unit klinik, 2 unit loket, 1 unit sepeda air, 2 unit dermaga, dan 1 unit kolam pancing.

Setelah melakukan penelitian di Kawasan Ciliwung Condet, penulis mendapati bahwa Kawasan Ciliwung Condet dapat berkembang apabila para stakeholder terkait saling bersinergi agar rencana Kawasan Condet menjadi destinasi wisata dapat terlaksana dengan baik. Selain itu, harus menjaga area sempadan sungai dan mengimplementasikan Rencana Detail Tata Ruang agar area resapan air bertambah dan resiko banjir dapat teratasi. Serta diperlukan peningkatan kapasitas moda transportasi yang melayani Kawasan Ciliwung Condet sehingga aksesibilitas menuju kawasan menjadi lebih mudah dan Mengintegrasikan berbagai acara baik bersifat yang bersifat kebudayaan, lingkungan dan lainnya dengan bentang Sungai Ciliwung Condet.

\section{REFERENSI}

Cooper, Fletcher, J., Gilbert, D., \& Wanhill, S. (1995). Tourism, Principles and Practice. London: Logman.

Lipman, G. a. (1996). Agenda 21 for the Travel and Tourism Industry. Towards Environmentally Sustainable Development. London: World Travel \& Tourism Council ; World Tourism Organization ; Earth Council.

Republik Indonesia. (2007). Undang-Undang Republik Indonesia Nomor 26 Tahun 2007 Tentang Penataan Ruang. Jakarta: Kementerian Sekretariat Negara.

Republik Indonesia. (2009). Undang-Undang Nomor 10 Tahun 2009 Tentang Kepariwisataan. Jakarta: Kementerian Sekretariat Negara.

Republik Indonesia. (2011). Peraturan Pemerintah Republik Indonesia Nomor 38 Tahun 2011 Tentang Sungai. Jakarta: Kementerian Sekretariat Negara.

Suwena I.K, N. W. (2017). Pengetahuan Dasar Ilmu Pariwisata. Denpasar: Pustaka Larasan. Syarifuddin, d. (2000). Sains Geografi. Jakarta: Bumi Aksara.

Taranggono, T. (1992). Cagar Budaya Condet : Suatu Kajian Ekologi Budaya di Wilayah Condet DKI Jakarta. Jakarta: Program Pascasarjana Universitas Indonesia.

Wardhono, F. I. (2015, Maret 7). Diambil kembali dari Slideshare.net: https://www.slideshare.net/fitriwardhono/penataan-ruang-kepariwisataan 
